\title{
Air Quality Plans for the Northern Region of Portugal: Improving Particulate Matter and Coping with Legislation
}

\author{
Borrego, C., Carvalho, A., Sá, E., Sousa, S., Coelho, D., \\ Lopes, M., Monteiro, A. and Miranda, A.I \\ CESAM \& Department of Environment and Planning, University of Aveiro, \\ Portugal
}

\section{Introduction}

Air quality is one of the environmental areas in which the European Union (EU) has been most active, in particular designing and implementing legislation on air quality and on the restriction of pollutant emissions to the atmosphere. The air quality Framework Directive (FD) (Directive 96/62/CE of 27 September 1996) established the obligations of the EU member states (MS) and redefined the guidelines for the assessment and management of air quality, namely the creation of an air quality management system comprising measuring networks, pollutant emission inventories and air quality modelling. Also, the FD states the obligation to elaborate and implement Plans and Programmes to improve air quality when the air quality standards are not fulfilled. The FD was transposed into the Portuguese legislation by the Decree-Law (DL) nr 276/99 of 23 July 1999. In order to state limits for specific pollutants, four "daughter" directives emerged later, which were also transposed to national legislation by three decree-laws (DL nr 111/2002, DL nr 320/2003, DL nr 351/2007). In May 2008, a new Directive on Ambient Air Quality and Cleaner Air for Europe (Directive 2008/50/EC) was published, integrating the former FD, three of the four previous "daughter" directives and one Council decision into a single document. The new Directive was transposed to national legislation by the Decree-Law nr 102/2010 of 23 September 2010. The European and national legislation regarding air quality management is illustrated in Figure 1.

The new directive (Directive 2008/50/EC) introduces new objectives for fine particles, but does not change existing air quality standards. Additionally, the application of numerical air quality models is highlighted as a fundamental tool to better assess and manage air quality. One of the main MS obligations is the implementation of Air Quality Plans (previously known as Plans and Programmes) when the air pollutant concentrations exceed the air quality standards in zones or agglomerations. The implementation of Air Quality Plans should be based on the design of measures to reduce the pollutant atmospheric concentrations and meet the legal requirements.

Exceedances of the thresholds of particulate matter with a $50 \%$ efficiency cut-off at $10 \mu \mathrm{m}$ aerodynamic diameter (PM10) have been reported by the majority of the EU member states, mainly in urban agglomerations, where human exposure is also higher (EEA, 2005). The 


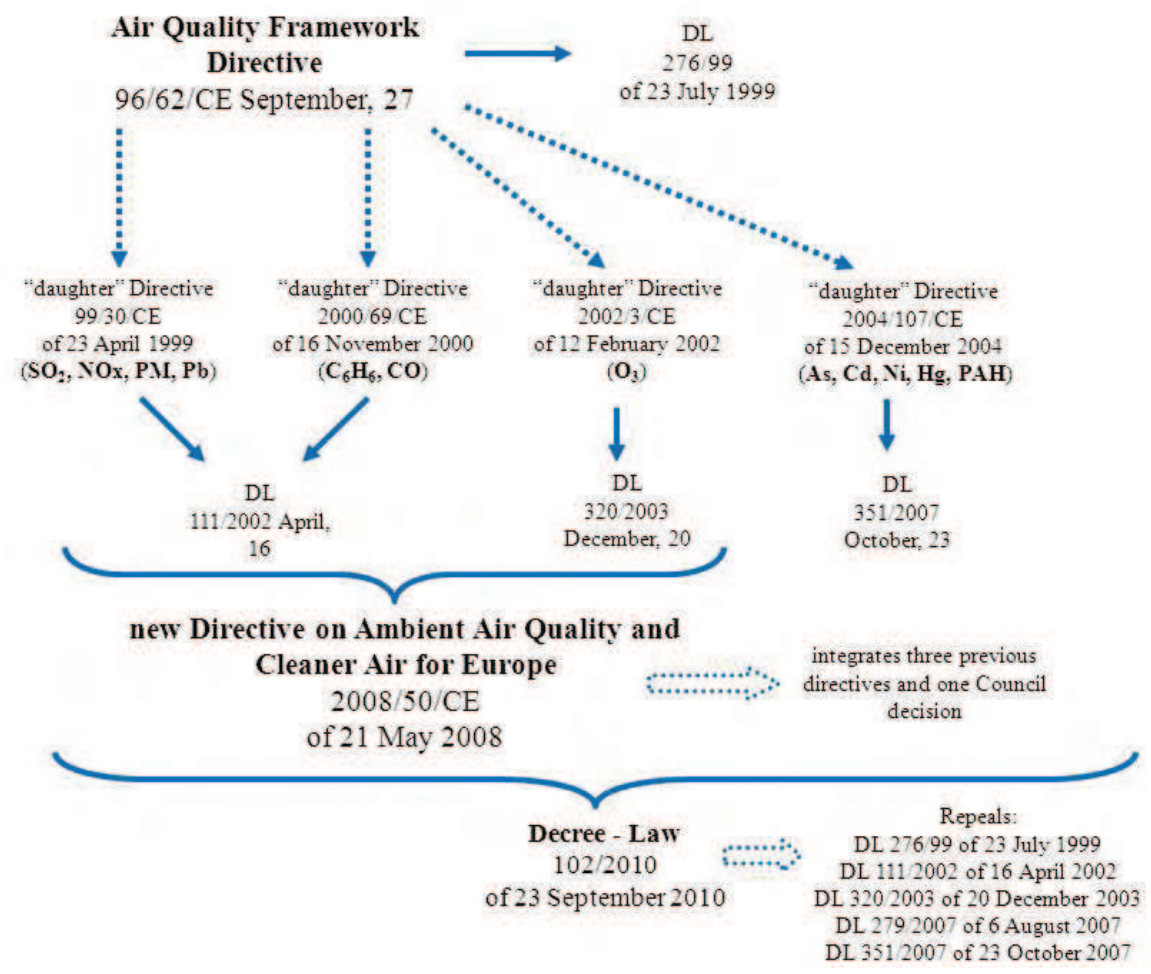

Fig. 1. European and Portuguese air quality legislation framework.

daily limit value for PM10 is $50 \mu \mathrm{g} \cdot \mathrm{m}^{-3}$ plus the margin of tolerance (LV+MT), and cannot be exceeded more than 35 times in a calendar year. Like what is being registered in the EU, over the last years Portugal has been surpassing the legislated limit values for PM10 concentrations in ambient air at several air quality monitoring stations (Monteiro et al., 2007), namely in the northern region.

The North Regional Coordination and Development Commission (CCDR-N) is the entity in charge of controlling and improving the air quality in the region. This is achieved through the development and implementation of Air Quality Plans to improve the PM10 levels, taking into account environmental benefits and economic costs of the proposed mitigation measures. In this chapter, data from the air quality monitoring stations between 2000 and 2007 (Air Quality Plans reference period) and the proposed PM10 emissions reduction measures are analysed. The environmental benefits of these measures for the improvement of the PM10 levels in the atmosphere are assessed through the application of a numerical modelling system.

\section{Air quality assessment over the northern region of Portugal, 2000-2007}

The northern region is divided into 2 zones (Norte Interior and Norte Litoral) and 4 agglomerations, namely Porto Litoral, Vale do Ave, Vale do Sousa, and Braga, defined 
according to the population density criteria settled by legislation (EU Directive 2008/50/EC). The air quality assessment for the period 2000-2007 imposed the development of Air Quality Plans in order to improve the PM10 levels in the agglomerations of Porto Litoral, Vale do Ave and Vale do Sousa.

\subsection{The air quality monitoring network}

The air quality monitoring network managed by the CCDR-N includes several background, traffic and industrial stations, with a total of 21 sites where PM10, among other air pollutants, is continuously measured (Borrego et al., 2008a). Figure 2 presents the northern region's zones and agglomerations with the respective location of the monitoring stations, together with the type of influence (traffic, industrial and background).

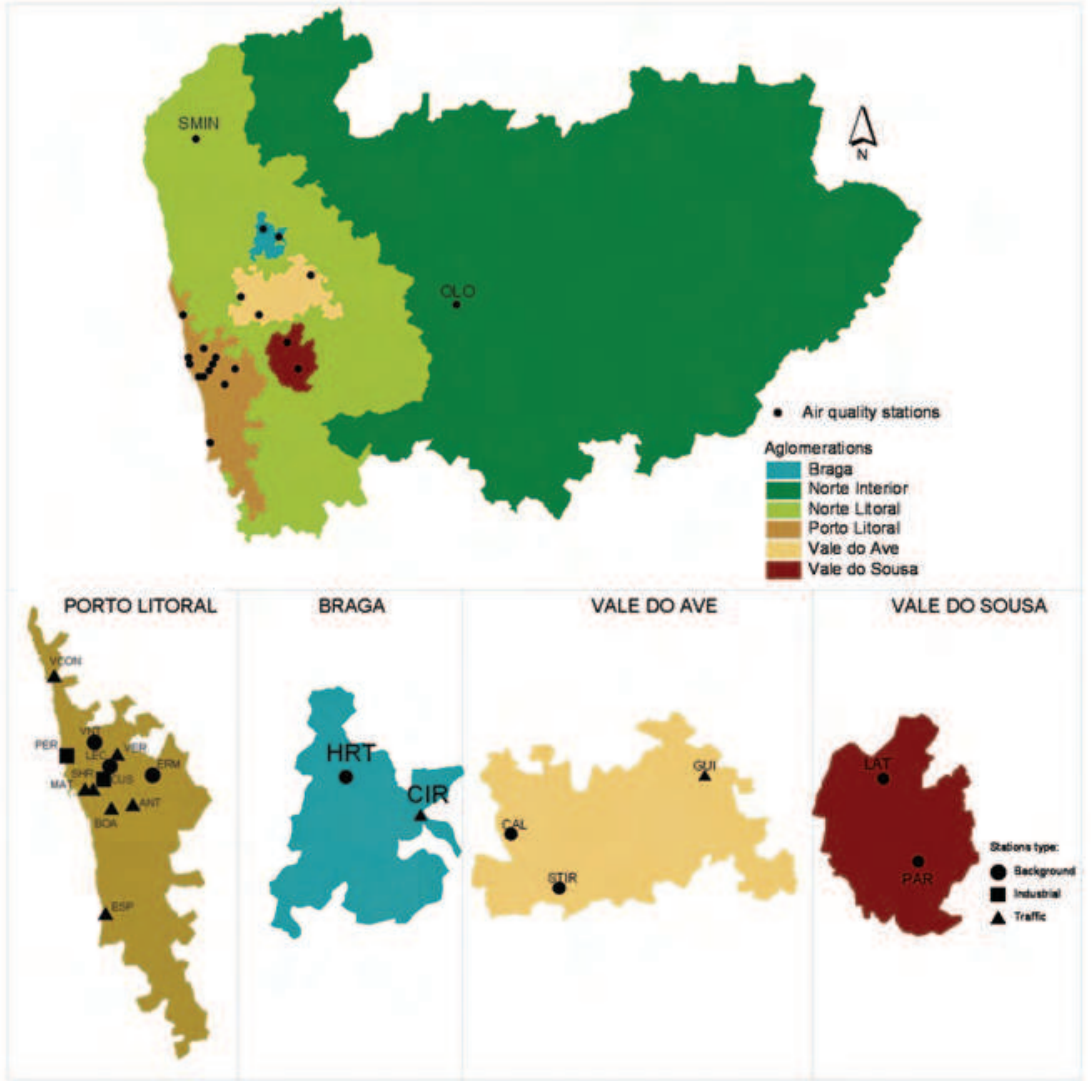

ANT-Antas; BOA-Boavista; MAT-Matosinhos; SHOR-Senhora da Hora; ESP-Espinho; VER-

Vermoim;PAR-Paredes; GUI-Guimarães; CIR-Circular Sul; ERM-Ermesinde; LAT-Centro Lacticínios; STIR-Santo Tirso; PER-Perafita; CUS-Custóias; VCON-Vila do Conde; LEC-Leça do Balio; VNT-Vila Nova da Telha;CAL-Calendário; HRT-Horto; SMIN - Senhora do Minho; OLO- Lamas D'Olo

Fig. 2. Representation of the CCDR-N PM10 air quality monitoring network and respective zones and agglomerations in 2007 
The agglomeration of Porto Litoral has the most extensive PM10 monitoring network, with 2 background, 7 traffic and 2 industrial sites. The other agglomerations are only covered by 2 , at maximum 3, stations. This network is, however, very recent. Before 2003, only $1 / 3$ of the stations were in operation. Due to the EU commitments and obligations the number of monitoring stations increased and between 2004 and 2007 the PM10 network improved substantially and reached the coverage exhibited in Figure 2.

Nevertheless, for the air quality diagnosis of the northern region the data collection efficiency has to be taken into account, but since not all of these stations fulfill the annual minimum PM10 data collection criteria required by legislation ( $85 \%$, considering around $5 \%$ of data loss due to calibration and maintenance procedures), they can not all be considered for the present data analysis. Figure 3 shows the number of monitoring stations with the required annual data collection efficiency from 2000 till 2007.

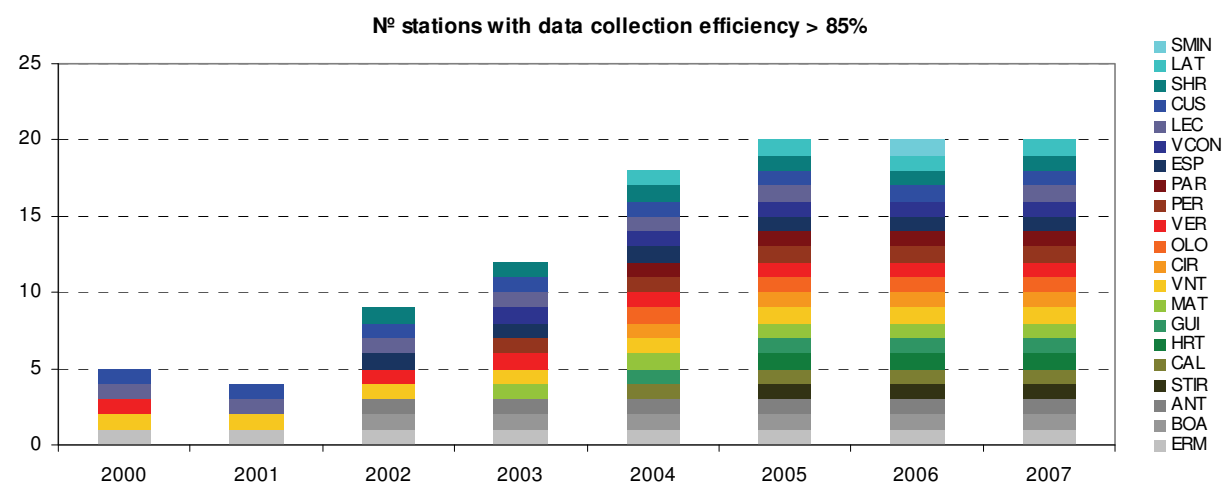

Fig. 3. Number of PM10 monitoring stations with annual data collection efficiency above $85 \%$.

After 2004 the number of monitoring stations with adequate data collection efficiency achieved an almost constant value, around 20 monitoring stations available for the analysis. In this sense, the following data analysis is based on data from these air quality stations, namely regarding the PM10 exceedances and general trends.

\subsection{PM10 data analysis}

A long-term evaluation of the PM10 concentration values registered in the northern region of Portugal is presented based on the hourly values collected over the study period of 20002007. This analysis was focused on the legislation accomplishment, as concerns the daily (50 $\left.\mu \mathrm{g} \cdot \mathrm{m}^{-3}\right)$ and annual $\left(40 \mu \mathrm{g} \cdot \mathrm{m}^{-3}\right)$ limit values for human health protection (EU Directive 2008/50/EC).

The fulfilment of the daily limit value is shown in Figure 4 over all the monitoring stations (Figure 4a) and considering only the background sites (Figure $4 \mathrm{~b}$ ).

Exceedances of the daily limit value (red line in the plots) are observed in the majority of the monitoring sites (Figure 4a), including background sites (Figure $4 \mathrm{~b}$ ) and over the entire analyzed period (2000-2007). Besides that, several values higher than $200 \mu \mathrm{g} \cdot \mathrm{m}^{-3}$ were registered in different monitoring stations, and at specific locations values above $400 \mu \mathrm{g} \cdot \mathrm{m}^{-3}$ and $800 \mu \mathrm{g} \cdot \mathrm{m}^{-3}$ can also be detected (in this case, due to a special episode of construction works close to the station). These data highlight that pollution due to particulate matter is a severe problem over this region, with systematic exceedances and particular high peaks/episodes. 


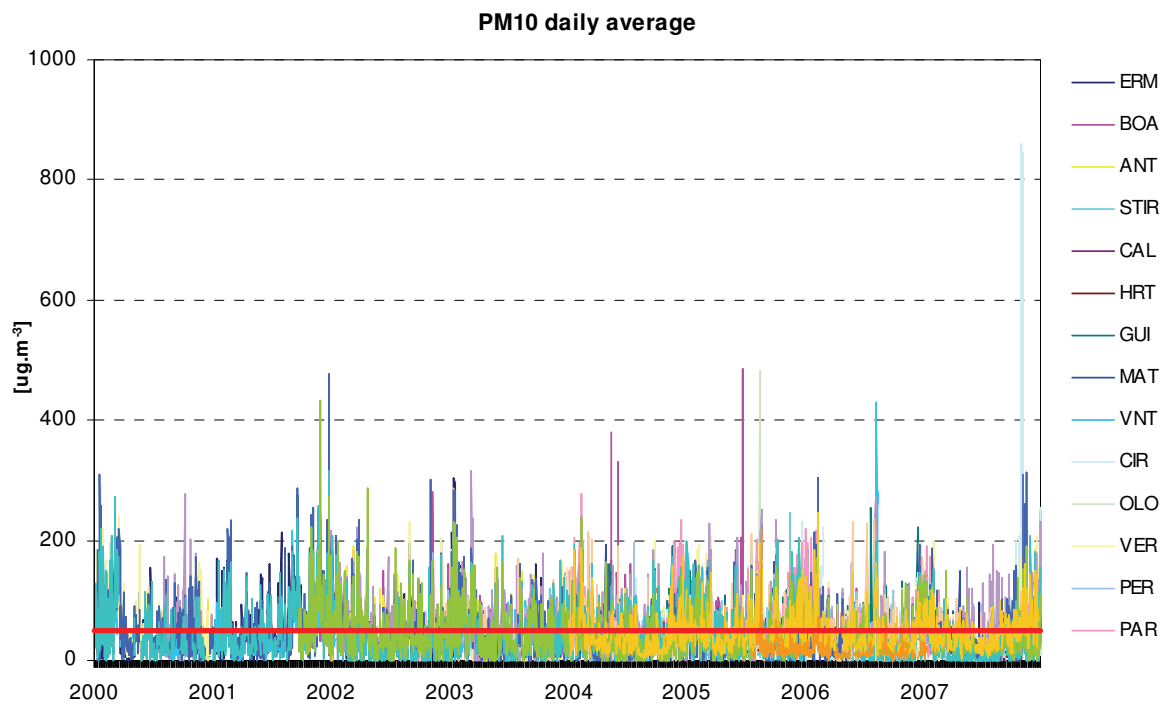

(a)

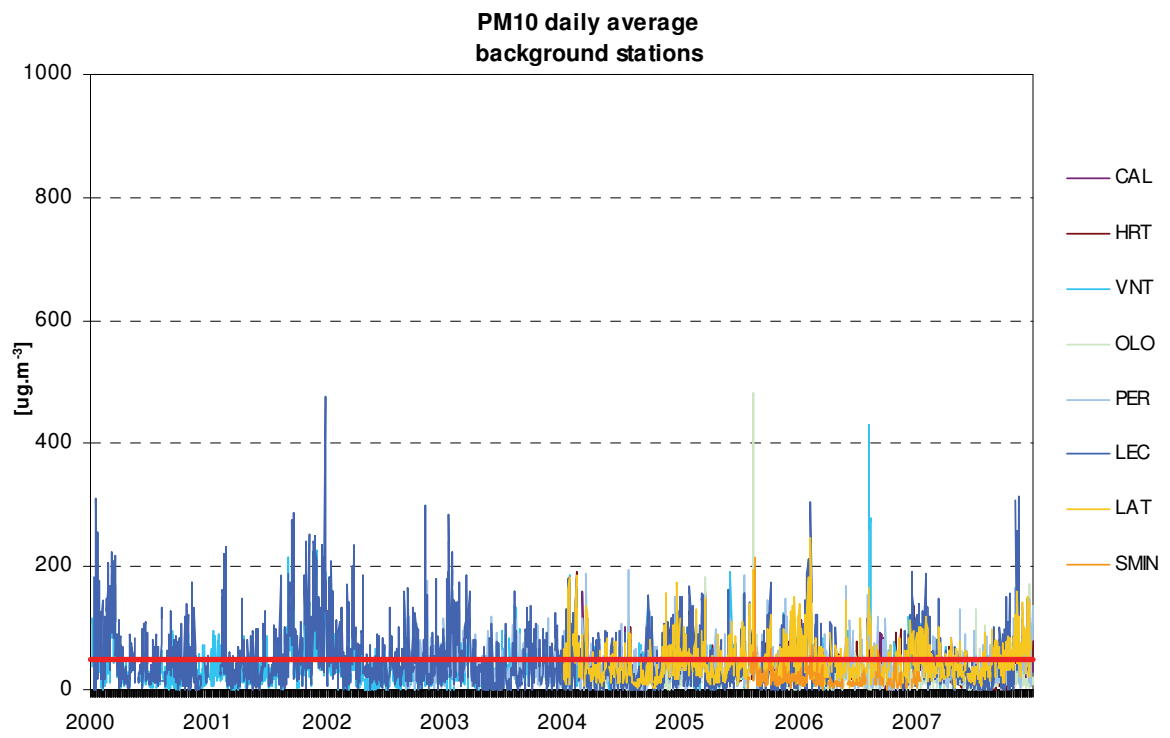

(b)

Fig. 4. PM10 daily average concentrations between 2000 and 2007 for all stations (a) and only considering the background stations (b). 
The number of days with daily limit exceedances, as well as the number of stations reporting these exceedances are shown in Figure 5, over the study period 2000-2007.

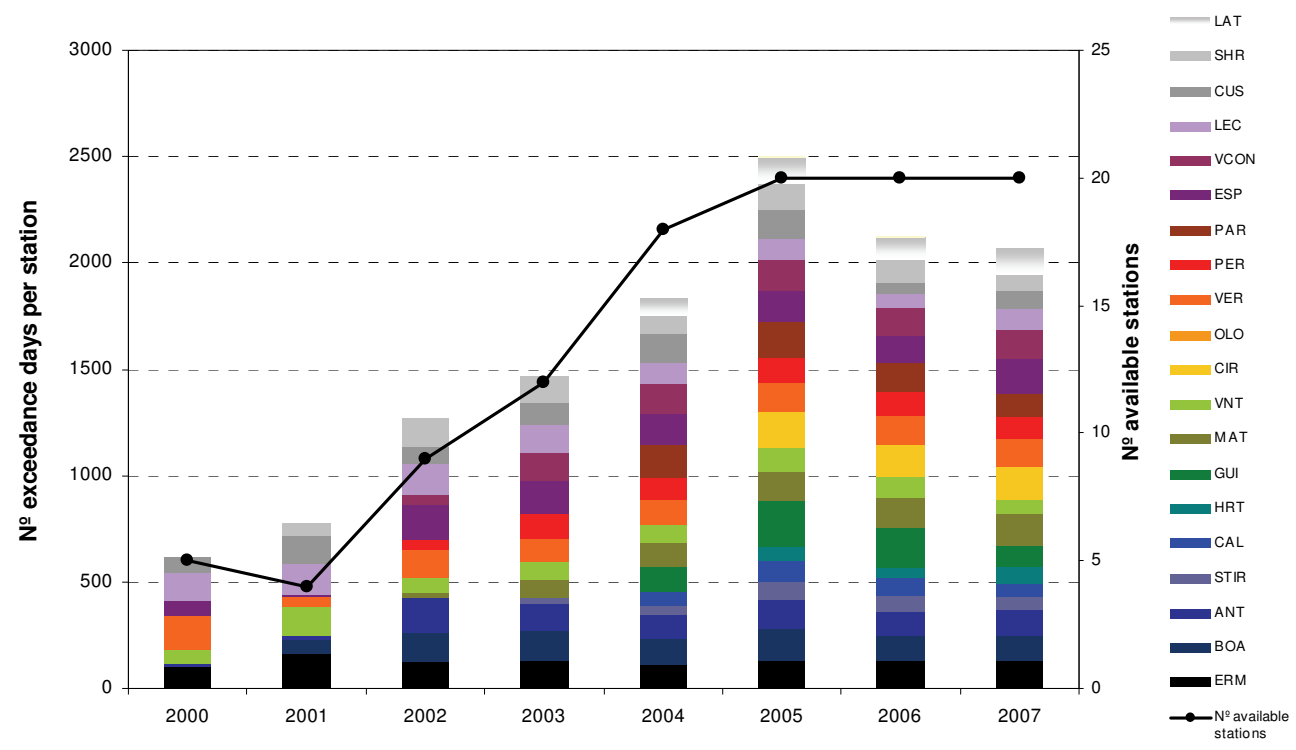

Fig. 5. Number of PM10 daily value exceedances over the 2000-2007 period for all available stations. The right axis presents the total number of available stations for each analyzed year in 2000-2007.

The number of stations with exceeding days increased over the 2000-2007 period, but this was mainly due to the increase in the number of available stations. The year 2005 was the most critical in terms of the number of stations that recorded concentrations above the limit value and of exceeding days.

Beyond the short-term impact, PM10 should also be assessed for the long-term. Legislation settles a limit value of $40 \mu \mathrm{g} \cdot \mathrm{m}^{-3}$ for PM10 annual average. Figure 6 shows the annual average of PM10 registered in each monitoring station during the analyzed period.

As well as with the daily average values, there are several stations that exceed the annual average limit value (Figure 6a). Nevertheless, the majority of these are traffic sites (Figure $6 \mathrm{~b})$, which explains the high levels detected (40-60 $\mu \mathrm{g} \cdot \mathrm{m}^{-3}$ on average). The unique exceptions are the background stations of LEC and CUS, whose high concentrations can be explained based on their suburban influence.

The total number of stations with exceedances of the annual limit value is summarized in Figure 7 for the study period (2000-2007). 


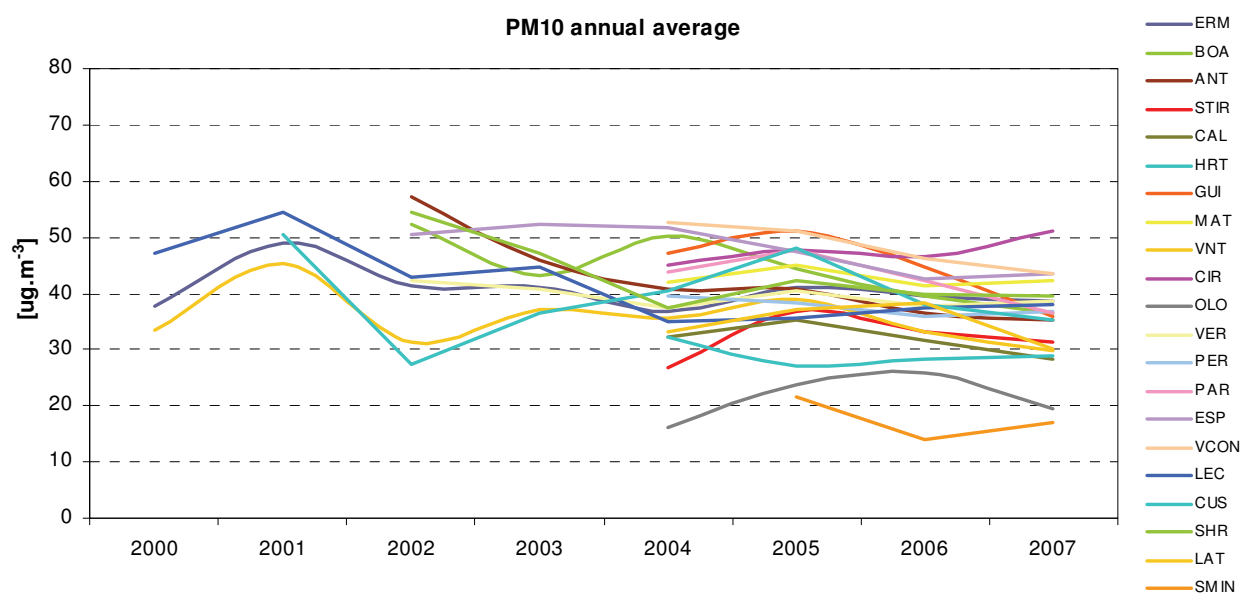

(a)

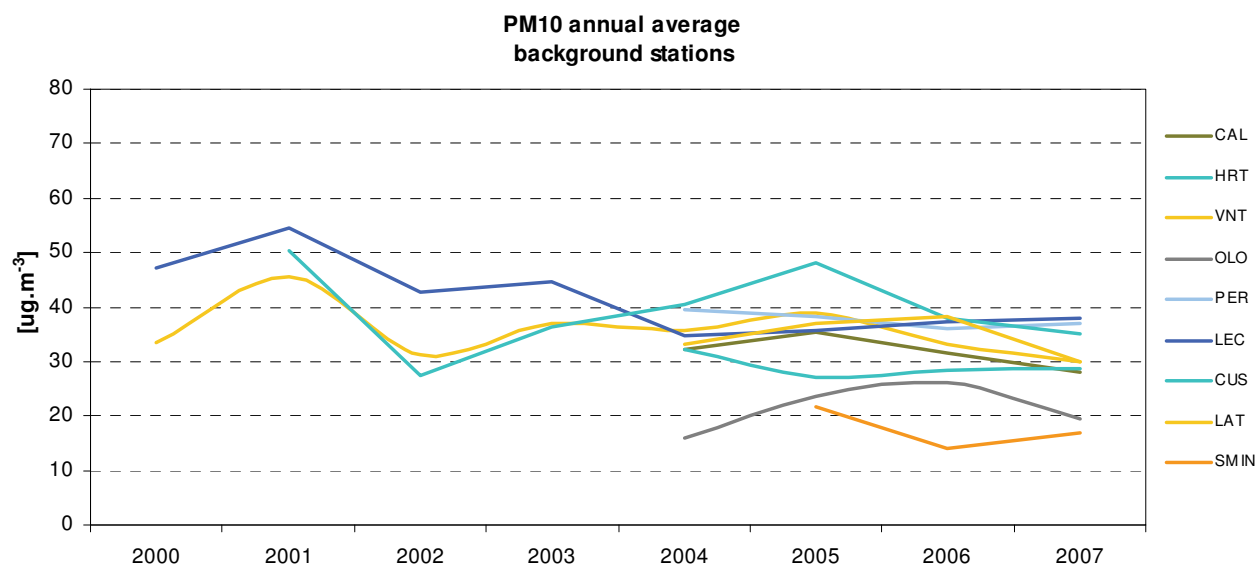

(b)

Fig. 6. PM10 annual average over the 2000-2007 period, for all available stations (a) and only for the background stations (b). 


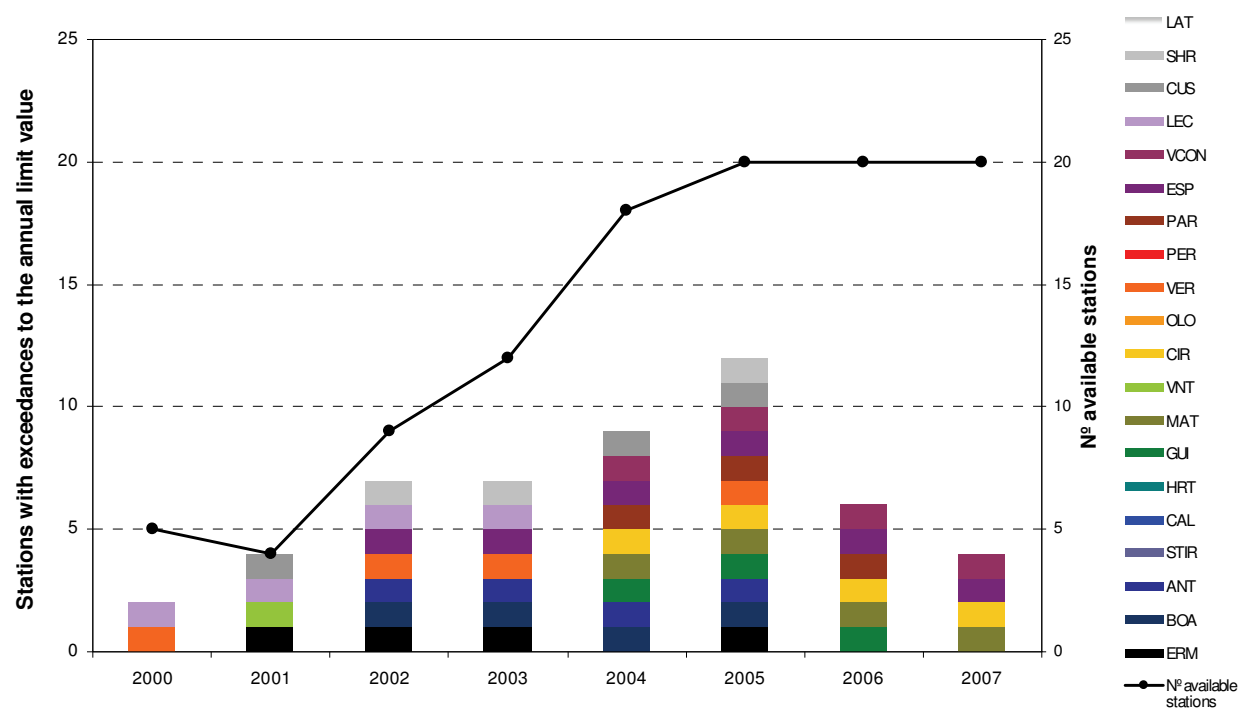

Fig. 7. Number of PM10 annual value exceedances over the 2000-2007 period for all the monitoring stations. The right axis indicates the total number of available stations for each analyzed year.

There is a clear trend to a reduction of PM10 annual values during the last two analyzed years (2006 and 2007). Until 2006, the majority of the stations registered exceedances every year, in particular between 2001 and 2003. 2005 was a critical year in terms of the number of stations with exceedances of the annual limit value.

There is a group of stations that have exhibited exceedances since they became active, namely, MAT, ESP and VCON. These three stations are located in the agglomeration of Porto Litoral.

In order to identify the more critical areas and respective agglomerations, the analysis of exceedances of the limit values was repeated grouping the stations by agglomeration (Figure 8).

The agglomeration of Porto Litoral presents the highest number of exceedances, for both daily and annual limit values, and during the entire study period (2000-2007). The remaining agglomerations (Braga, Vale do Ave and Vale do Sousa) registered exceedances of both limit values only after 2004 , although, in fact, the monitoring stations were only active after this date.

The exceedances of the PM10 limit values occurred in traffic, industrial, urban and suburban background stations with an estimated exposed population of around 500,000 inhabitants. This situation highlights the need for the design and implementation of Air Quality Plans to improve the PM10 levels in the region. The next section presents the measures that were selected and studied in order to reduce the PM10 emissions to the atmosphere in the northern region of Portugal. 


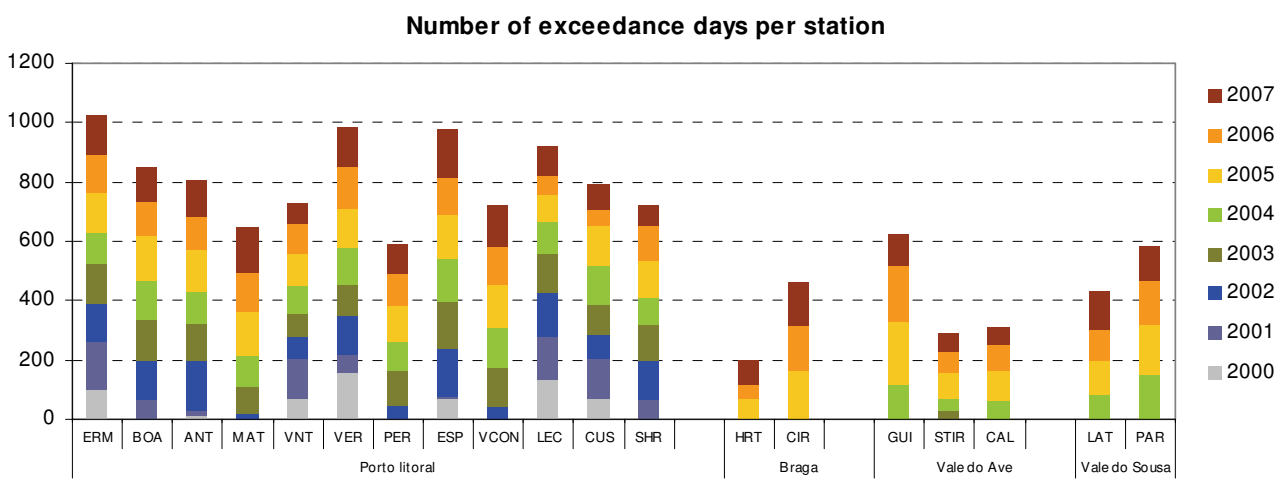

(a)

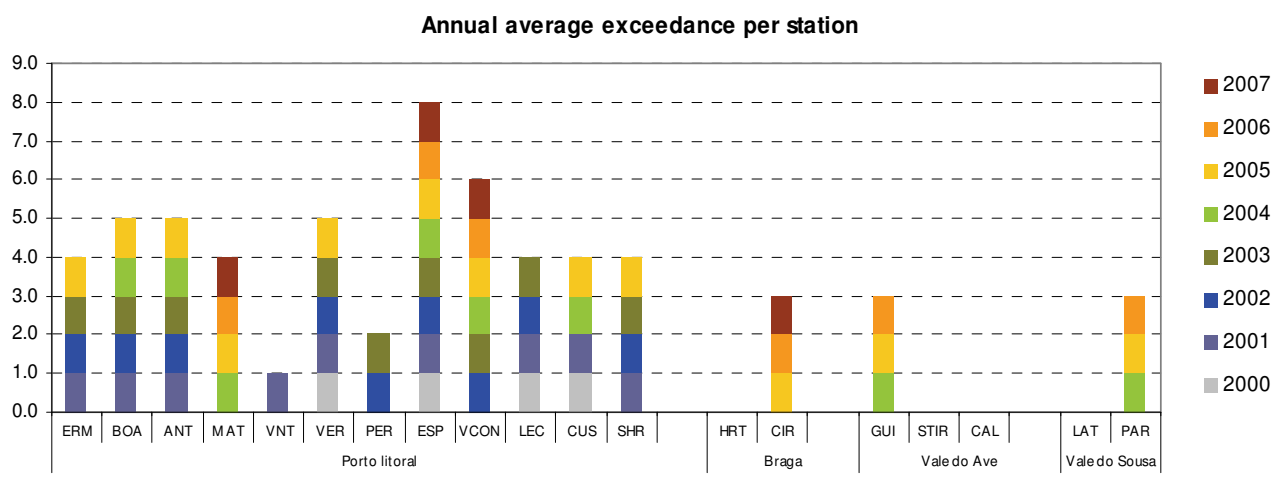

(b)

Fig. 8. PM10 exceedances for the daily (a) and annual (b) target values for each station within the analyzed agglomerations.

\section{Measures to reduce the PM10 emissions over the northern region of Portugal}

As previously mentioned, the development of Air Quality Plans for the agglomerations of Porto Litoral, Vale do Ave and Vale do Sousa is mandatory. The design of efficient Air Quality Plans implies the comprehension of the sources of PM10 affecting these agglomerations and the identification of the main sources of the measured levels. The PM10 concentrations can derive from natural or anthropogenic emission sources. Studies performed over the last decade consider that natural emissions could make a significant contribution to the PM10 levels. The anthropogenic sources of PM10 are usually located in urban and industrial areas. Over the urban areas, the emission of PM10 is closely related to residential combustion (Borrego et al., 2010a), construction and road traffic. Traffic emissions are due not only to the 
direct exhaust of the vehicles, but also to brakes wear, road abrasion, tyre wear and road dust re-suspension. According to Ketzel et al. (2005), dust re-suspension accounts for about 50 to $85 \%$ of the total emissions from traffic-related emissions. The PM10 industrial sources include ceramics, clinker and cement production or mining processes (Rodriguez, 2002).

Based on the emission inventory for the northern region (Borrego et al., 2008b) traffic, industrial and commercial activity (restaurants), residential combustion and construction sites were identified as the main anthropogenic sources of PM10 in those agglomerations. Figure 9 presents the main PM10 emission sources at national level and in the northern region.

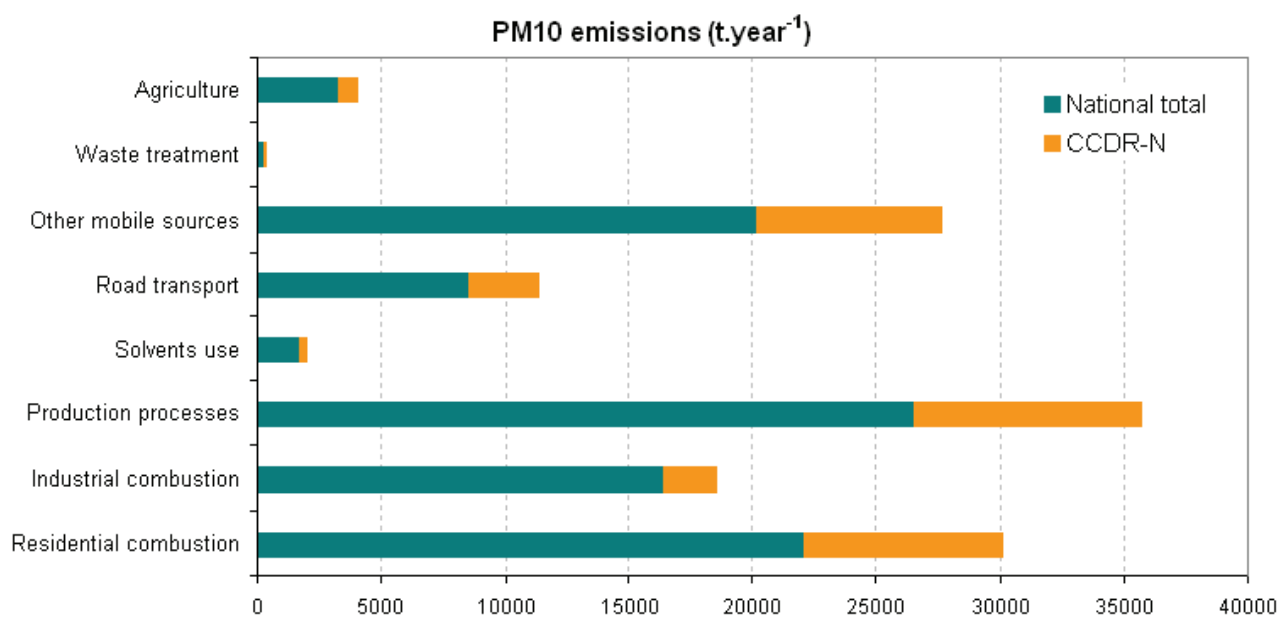

Fig. 9. PM10 emissions for different sectors at national level and over the northern region (CCDR-N) (Borrego et al., 2008b).

Taking into account the main emission sources, several mitigation measures to reduce PM10 levels in the three agglomerations were defined according to their environmental benefits and economic costs (Borrego et al., 2008a). These measures were discussed with the entities involved in their implementation and finally a list of selected measures was designed. The Execution Programme (EP), which is the Portuguese legal document that promotes and enforces the application of the emission reduction measures, describes these selected measures in detail. Figure 10 summarizes the entire process from the elaboration of the Air Quality Plan to the Execution Programme.

The measures included in the EP result from multiple contacts and meetings established between the CCDR-N and the entities identified as responsible for their implementation. The number of local, regional and national entities participating in the selection and implementation of the measures to reduce PM10 emissions in the northern region rose to 35. Several protocols were signed with the local and regional entities to formalize the implementation of the selected measures within the EP framework. These measures were grouped in three main sectors: (i) traffic; (ii) industry; and (iii) residential combustion. A brief description of the measures considered in the EP is presented below. 


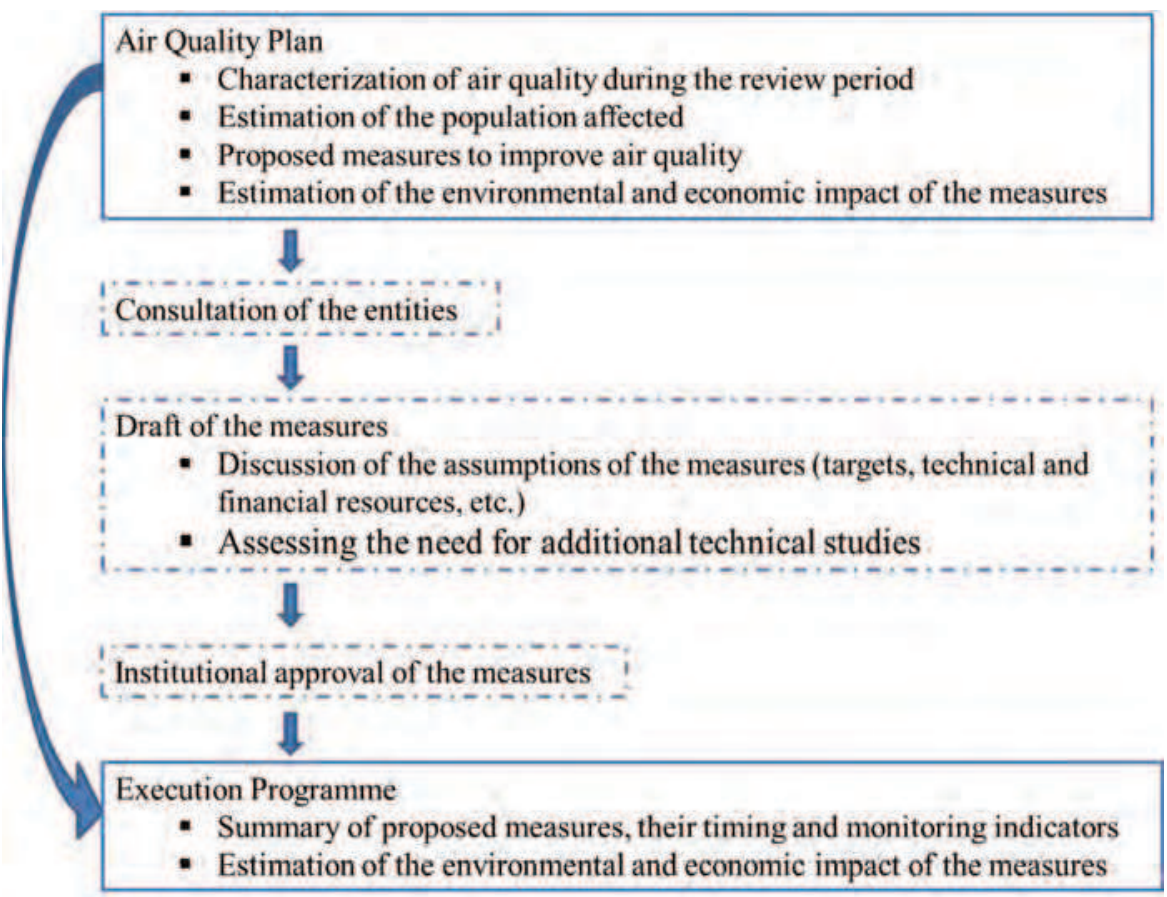

Fig. 10. Process related to the design of the Execution Programme.

\subsection{Traffic sector}

- Improving the public transport system

The improvement of the public transport system aims to reduce the number of kilometers travelled, as being economically attractive and at the same time reducing PM10 emissions.

- $\quad$ Low Emission Zones (LEZ)

LEZ are urban spaces where circulation of the most polluting heavy diesel vehicles (with emissions over a certain level or not meeting a certain European emission standard - Euro standards) is restricted or, in some cases, charged according to their emission levels.

- Installation of particle filters on heavy vehicles

The percentage of heavy vehicles in comparison with the total number of vehicles in circulation is small, although, the associated PM10 emissions are significant, being one of the categories that most contribute to the PM10 traffic emissions. In diesel engines, the introduction of filters reduces by $90 \%$ the emissions of particulate matter (Tente et al., 2011). The Portuguese government launched legislation to support, among others things, the retrofitting of vehicles with particulate filters. Financial incentives to support the renewal and update of the public transportation fleet were also launched.

- $\quad$ Renewal of the municipal solid waste management fleet

According to an inquiry held in the municipalities, over $80 \%$ of the fleet of municipal solid waste collection vehicles was old (prior to 2000). Thus, the renewal of that fleet 
was proposed through the introduction of emission control systems, including particulate filter systems with exhaust gas recirculation or the replacement of old vehicles by modern ones that meet most recent Euro standards.

- Introduction of public fuel stations for natural gas

According to the Portuguese Association of Natural Gas Vehicles in Portugal, in 2007 there were 377 natural gas vehicles, most of which were owned by public transport companies and municipalities. At national level, there was only one fuel station for natural gas for the general public, and the remaining four were inactive or were for private use. An increase in supply will tend to encourage the public to purchase more such vehicles, thereby reducing the emission of particulate matter. It is intended to build a public natural gas station in the northern region.

- Street sweeping and washing

In urban areas, the PM10 emissions from resuspension caused by road traffic are comparable with or even larger than those from exhaust gases (Amato et al., 2009). Consequently, street sweeping and washing contributes to the removal of the particles deposited on the pavement and reduces the resuspension of such material. When water adheres to deposited particles, it increases their mass and surface tension forces, decreasing the likelihood of suspension and transport, especially as cohesion of wetted particles often persists after the water has evaporated due to the formation of aggregates (Amato et al., 2009).

\subsection{Industrial sector}

- Publication of a legal diploma with new emission limit values (ELV) for stationary sources

The reduction of the current emission limit value (ELV) for particulate matter coming from stationary sources associated with industrial and commercial activities represents a large contribution to PM10 emission decrease in the northern region of Portugal.

Moreover, enhanced surveillance of point sources will have a major role in fulfilling the legal obligations in this regard. The obligation to comply with more stringent ELV will lead, in some cases, to the need for installation of emission reduction systems or their replacement with more efficient ones.

\subsection{Residential combustion sector}

- Certification of residential combustion equipment

Residential combustion is an important source of particulate matter emissions. Borrego et al. (2010a) estimated an 18\% contribution of this residential combustion to the total PM10 emissions in Portugal, and that $98 \%$ of these originate from the burning of biomass.

Consequently, the regulation of this sector, particularly the certification of equipment with lower PM10 emission rates, will contribute to air quality improvement (both outdoors and indoors). The implementation of this measure follows a complex process that needs the involvement of several entities and stakeholders.

\subsection{Summary}

The PM10 emission reduction was estimated for each described measure based on different approaches and methodologies. For instance, for the traffic sector measures the emission 
reduction was estimated using national emission factors for different age and circulation speeds of each vehicle. At the end, the foreseen emission reduction values are: for the residential and commercial combustion sector $92 \%$ for all the northern region; for the industry sector $50 \%$ for all the northern region, excluding Vila Nova de Famalicão (45\%) and Matosinhos (18\%) municipalities; for the traffic sector, the mean reduction value is $14 \%$, with a maximum reduction of $28 \%$ and the lowest reduction of $1 \%$.

Table 1 summarizes the overall PM10 emission reduction, including the base scenario (no measures) and the reduction scenario (concerning traffic, industrial processes and residential combustion).

\begin{tabular}{|c|c|c|c|}
\hline Sector & $\begin{array}{c}\text { PM10 Emissions } \\
\text { (Base scenario) } \\
\text { (ton.year-1) }\end{array}$ & $\begin{array}{c}\text { PM10 Emissions } \\
\text { (Reduction scenario) } \\
\text { (ton.year-1) }\end{array}$ & $\begin{array}{c}\% \\
\text { reduction }\end{array}$ \\
\hline $\begin{array}{c}\text { Road } \\
\text { traffic }\end{array}$ & 32899 & 31254 & $5 \%$ \\
\hline Industry & 1476 & 1314 & $11 \%$ \\
\hline Residential & 382 & 378 & $1 \%$ \\
\hline Total & 34747 & $\mathbf{3 2 9 4 6}$ & $\mathbf{5 . 1 \%}$ \\
\hline
\end{tabular}

Table 1. Total PM10 emissions for each sector for the base and the reduction scenarios.

The implementation of these measures accounts for a $5.1 \%$ overall reduction of the total northern region PM10 emissions.

In addition to these main measures, additional measures were also considered and implemented, namely regarding the reduction of dust emissions from construction sites and specific measures related to environmental education.

The construction works represent a significant source of particulate matter in the atmosphere, leading to air quality problems at local level. Different approaches can be implemented in order to reduce the PM10 emissions generated by this activity (e.g., washing roads and work fronts, especially on dry and windy days and in unpaved areas). Several actions have been compiled in a manual that was distributed among the construction companies to proceed to actions of training and awareness. The associations of industrial construction also have an important role in dissemination of best practice among their members. Municipalities should also implement these practices under the Municipal Regulation of Building and Urbanization.

Many measures to reduce PM10 are related to changes in habits and behaviours. Therefore, education and recommendations to the population, entrepreneurs and municipalities are the keys to acquiring habits with reduced environmental impact. Environmental education and awareness also allows a greater social acceptance of the measures to reduce PM10 emissions and, consequently, greater public support. The execution of these initiatives is primarily a responsibility of the CCDR-N and the municipalities involved, in cooperation with other agencies and associations that are closer to specific target groups (e.g., industry associations, schools), and is being conducted through the media, forums, workshops, etc.

Several authorities, institutions and 21 municipalities were involved in the implementation of the selected measures, which will achieve an overall cost of almost $€ 45$ million. 
Engagement in the application of all the measures constitutes an important step forward to achieve the main goal of PM10 emission reduction and air quality improvement over the northern region of Portugal.

\section{Air quality modelling}

Estimation of the PM10 emissions reduction is not, however, enough to assess their effects on the air quality of the region. In order to better evaluate the impact on the northern region's air quality resulting from the selected PM10 emission reduction measures, a numerical modelling system has been applied.

The Air Pollution Model (TAPM) was selected since it is suitable for long term simulations (e.g., one year), has a user friendly interface and runs fast. Additionally, TAPM has already been applied and validated in several studies over Portugal (Ribeiro, 2005; Bandeira et al., 2011) and specifically over the northern region (Borrego et al., 2010b).

\subsection{The air quality model}

The Air Pollution Model (TAPM) is a 3-D Eulerian model which predicts meteorology and air pollution concentrations, based on fundamental fluid dynamics and scalar transport equations. Technical details of the model equations, parameterisations and numerical methods are described by Hurley et al. (2005). The model integrates two modules: the meteorological and the air pollution component. The first predicts the meteorological parameters that are one of the inputs for the second, which predicts the concentration and deposition of the air pollutants. In the TAPM meteorological component, global databases of terrain and land use from the Earth Resources Observation Systems (EROS), surface temperature from the US National Centre for Atmospheric Research (NCAR), and synoptic conditions from the Limited Area Prediction System (LAPS) and Global Analysis and Prediction (GASP) models from the Bureau of Meteorology (BOM) were used.

Besides the meteorological outputs, the air pollution component considers the air pollutants emissions from several sources, such as: point sources, line sources, gridded surface emissions, biogenic surface emissions, among others. TAPM has some options regarding pollution calculations, including chemistry mode with sulphur and fine particle chemistry. In the chemistry mode, gas-phase is based on a semi-empirical mechanism entitled the Generic Reaction Set (GRS), having 10 reactions for 13 species.

TAPM includes a nested approach regarding meteorology and air pollution, for computational efficiency, with the pollution grids optionally being able to be configured for a sub-region and/or at finer grid spacing than the meteorological grid, which allows the user to zoom in to an urban region of interest quite rapidly. This option is particularly important for this study. Meteorological and pollution outputs are in various formats and include vertical and temporal profiles for several parameters (Hurley et al., 2005).

\subsection{Air quality modelling application}

In order to investigate the impact of the designed PM10 reduction measures on the air quality of the northern region, the TAPM was applied over the study region, which includes the agglomerations of Porto Litoral, Vale do Ave and Vale do Sousa where the PM10 concentrations exceeded the legislated limit values. The application considered three simulation domains through the use of the nesting approach: the outer domain covers an 
area of $1080 \times 1080 \mathrm{~km}^{2}$ with a spatial resolution of $43.2 \times 43.2 \mathrm{~km}^{2}$, the second domain covers an area of $360 \times 360 \mathrm{~km}^{2}$ with a spatial resolution of $14.4 \times 14.4 \mathrm{~km}^{2}$ and the inner domain with an area of $120 \times 120 \mathrm{~km}^{2}$ has a spatial resolution of $4.8 \times 4.8 \mathrm{~km}^{2}$. TAPM was applied along the year 2004, which was chosen as the base year for the analysis of the impact of the selected measures, for two different emissions scenarios: base scenario and reduction scenario. For the base scenario, annual emissions were obtained from the Portuguese national inventory and spatially downscaled to the sub-municipality level for each pollutant and for each activity sector. The national emissions inventory takes into account annual emissions from line sources (streets and highways), area sources (industrial and residential combustion, solvents and others) and large point sources. The annual emission data for each pollutant and activity sector were spatially and temporally disaggregated in order to obtain the resolution required for the selected simulation domains. For the reduction scenario, the PM10 emission values were estimated based on the implementation of the designed reduction measures, which were previously described. The background concentrations required by the model were obtained estimating the average values of the background air quality stations of the study area for 2004.

The meteorological and air quality simulations were performed for the defined domains over the study region. The validation of the base scenario simulation was performed for the innermost domain, which includes all the air quality stations. Three quality indicators have been used to evaluate the TAPM performance over the study region, namely: Index of Agreement (IOA) (Eq.1), Measures of Skill (SKILLR) (Eq.2) and Bias (BIAS) (Eq.3).

Index of Agreement:

$$
I O A=1-\frac{\sum_{i=1}^{N}\left(P_{i}-O_{i}\right)^{2}}{\sum_{i=1}^{N}\left(\left|P_{i}-O_{\text {mean }}\right|+\left|O_{i}-O_{\text {mean }}\right|\right)^{2}}, \text { where } O_{\text {mean }}=\sum_{i=1}^{N} O_{i}
$$

Measures of Skill:

$$
S K I L L_{R}=\frac{R M S E}{O_{\text {std }}}, \text { where } O_{\text {std }}=\sqrt{\frac{1}{N-1} \sum_{i=1}^{N}\left(O_{i}-O_{\text {mean }}\right)^{2}} \text { and } R M S E=\sqrt{\frac{1}{N} \sum_{i=1}^{N}\left(P_{i}-O_{i}\right)^{2}}
$$

Bias:

$\mathrm{O}_{i} \rightarrow$ observed values

$$
B I A S=\frac{\sum_{i=1}^{N}\left(P_{i}-O_{i}\right)}{N}
$$

$P_{i} \rightarrow$ predicted values

RMSE $\rightarrow$ Root Mean Square Error

The Index of Agreement (IOA) gives the difference between the predicted values and the observed ones. If this value is higher than 0.5 the model presents a good performance. RMSE values lower than the Standard Deviation of the observed values $\left(O_{s t d}\right)$ also indicate a good performance of the model.

The BIAS indicates if the model follows the variations of the observed values: if positive, the model overestimates the results, and if negative the model underestimates the results. 


\subsection{Air quality modelling system performance}

A statistical analysis of the model's performance was made. The meteorological module was evaluated against the measured values of temperature and horizontal wind components (U and V) at two different meteorological stations of the northern region (Pedras Rubras and Viana do Castelo meteorological stations). Table 2 summarizes the model's performance for temperature and wind at the two weather stations.

\begin{tabular}{|c|c|c|c|c|c|c|}
\cline { 2 - 7 } \multicolumn{1}{c|}{} & \multicolumn{3}{c|}{ Pedras Rubras } & \multicolumn{3}{c|}{ Viana do Castelo } \\
\cline { 2 - 7 } \multicolumn{1}{c|}{} & TEMP & $\mathrm{U}$ & $\mathrm{V}$ & TEMP & $\mathrm{U}$ & $\mathrm{V}$ \\
\hline IOA & 0.94 & 0.79 & 0.86 & 0.91 & 0.66 & 0.74 \\
\hline SKILL $_{\mathbf{R}}$ & 0.46 & 1.03 & 0.83 & 0.63 & 1.39 & 1.00 \\
\hline BIAS & 0.46 & -0.83 & -0.21 & -0.94 & -0.76 & -0.48 \\
\hline
\end{tabular}

Table 2. TAPM performance statistics for temperature $\left({ }^{\circ} \mathrm{C}\right)$ and horizontal wind components (m.s $\left.\mathrm{s}^{-1}\right)$.

TAPM shows a good performance simulating temperature and both wind components, with no significant biases, low SKILL $L_{R}$ and high IOA for both meteorological stations. The Pedras Rubras simulation presents a slightly better performance than Viana do Castelo. These results highlight that the TAPM model is capable of simulating the main meteorological conditions over the study region.

The same statistical indicators have been applied for the PM10 simulated values at the air quality stations that presented exceedances of the limit values. Figure 11 presents the IOA, BIAS and SKILL for each air quality station, for the base scenario simulation.

According to Figure 11, only some air quality stations have an IOA higher than 0.5, highlighting the model's difficulty in simulating the PM10 values over the study region. The negative BIAS over all the analyzed air quality stations reveals a clear underestimation of the measured PM10 concentrations. The SKILL also presents a very poor score. These results show that the TAPM model has some difficulties in simulating the PM10 levels over the study region. This fact can be related to the complex topography of the study domain and uncertainty related to the PM10 emissions estimation. PM10 is one of the most difficult pollutants to simulate by air quality modelling systems. In addition, the TAPM uses a very simple chemical mechanism that to some extent may explain the poor results for the PM10 simulation.

Notwithstanding this evaluation, TAPM can be an interesting tool for decision-makers to assess the efficiency of the measures selected and included in the Air Quality Plans. Since the model can rapidly simulate different emission scenarios, the decision-making can be facilitated through the study of the differences between scenario results, allowing their relative comparison, instead of the analysis of the absolute predicted values.

\subsection{Air quality results for the emission reduction scenario}

In order to study the environmental effects of the application of the selected PM10 mitigation measures on the air quality of the northern region of Portugal, the reduction scenario was also simulated with TAPM. Figure 12 shows the spatial differences between the reduction and the base scenarios in terms of the annual mean PM10 concentrations (absolute values (a) and percentages of change (b)). 


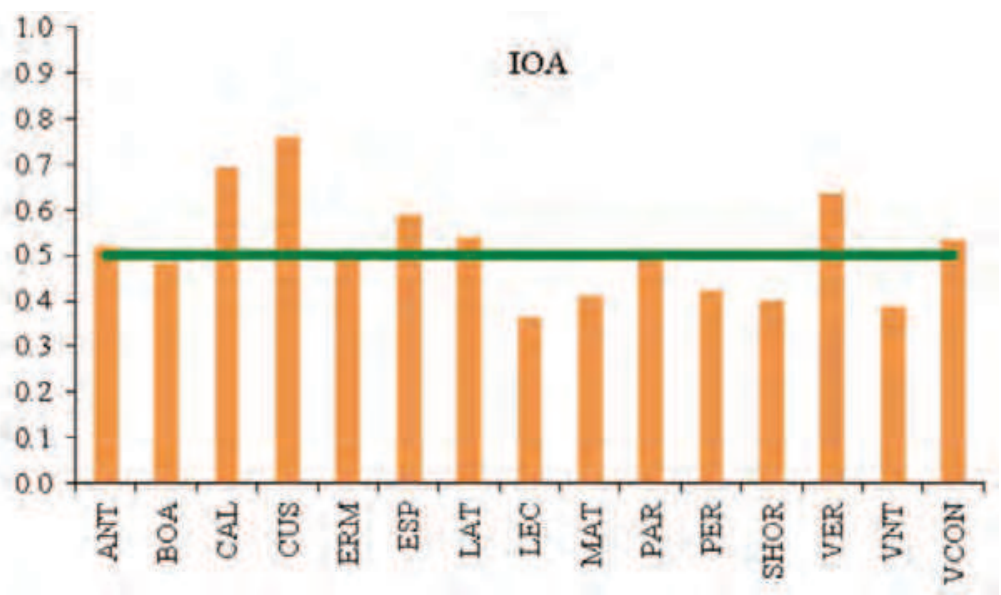

BIAS
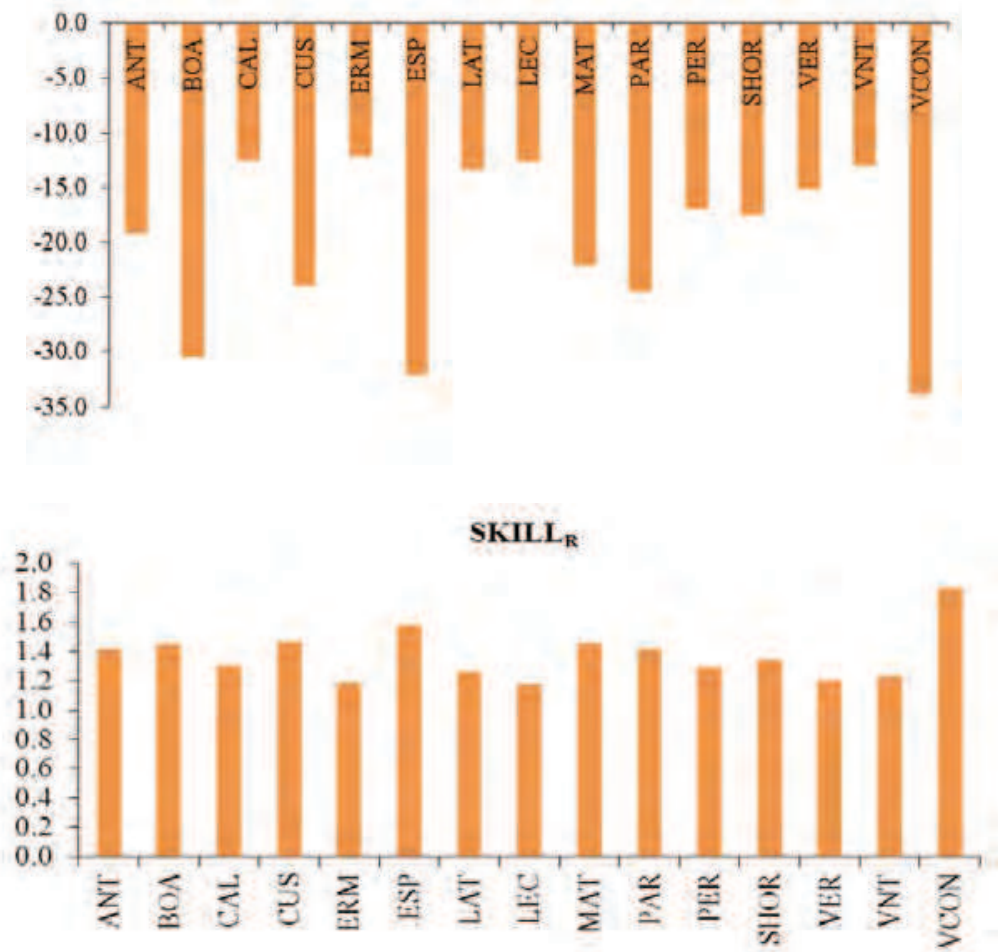

Fig. 11. IOA, BIAS and SKILLR statistical indicators for each air quality station for the TAPM base scenario simulation for the year 2004 regarding PM10 daily concentrations. 


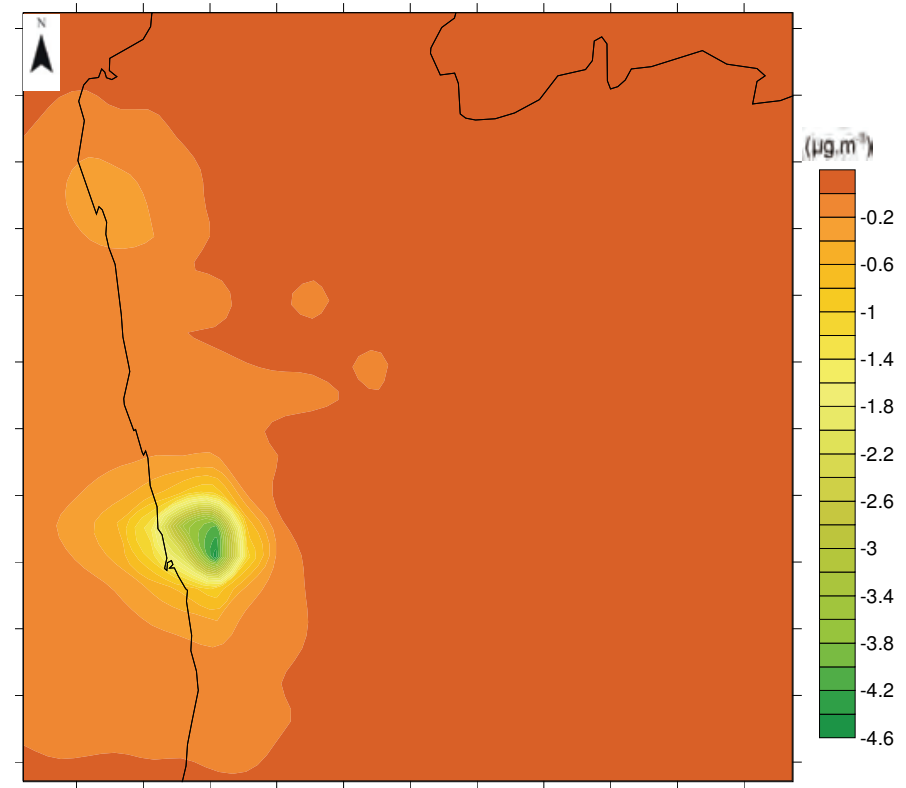

(a)

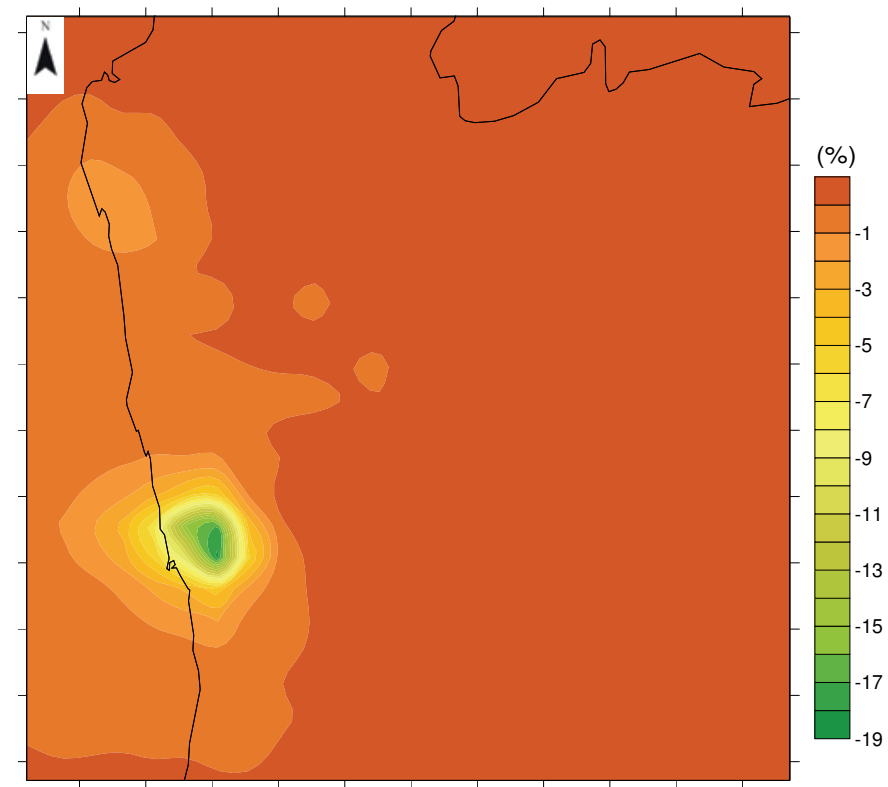

(b)

Fig. 12. PM10 annual mean concentration differences between the reduction scenario and the base scenario in terms of absolute (a) and relative changes (in \%) (b). 
According to Figure 12, the maximum absolute reduction is achieved over the Porto region and reaches almost $5 \mu \mathrm{g} \cdot \mathrm{m}^{-3}$, which corresponds to a $19 \%$ reduction of the PM10 average concentrations.

Another way to study the effects of the implementation of the reduction measures consists in estimating the reduction obtained by comparing the results from each scenario simulation (base and reduction) for each day, and then applying this reduction profile to the daily measured values at the monitoring stations. This approach has only been applied to the air quality stations with IOA higher than 0.5 .

Figure 13(a) illustrates the measured annual mean and the annual mean after the application of the reduction profile, and Figure 13(b) represents the number of observed exceedances of the daily limit value (plus the margin of tolerance for 2004) and the number of exceedances after the application of the reduction profile.

\section{Annual mean}

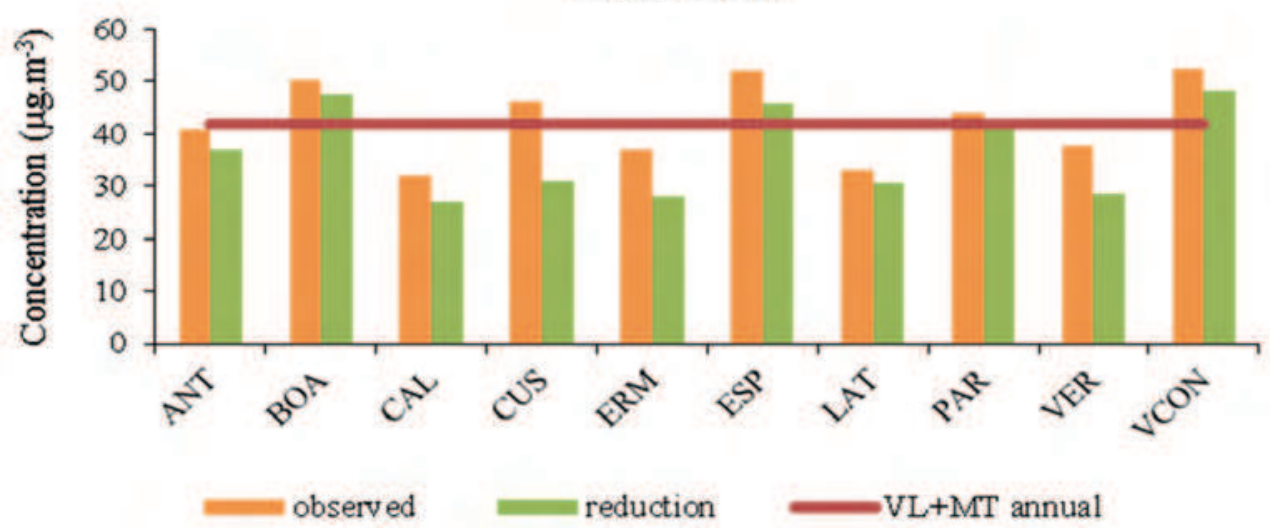

(a)

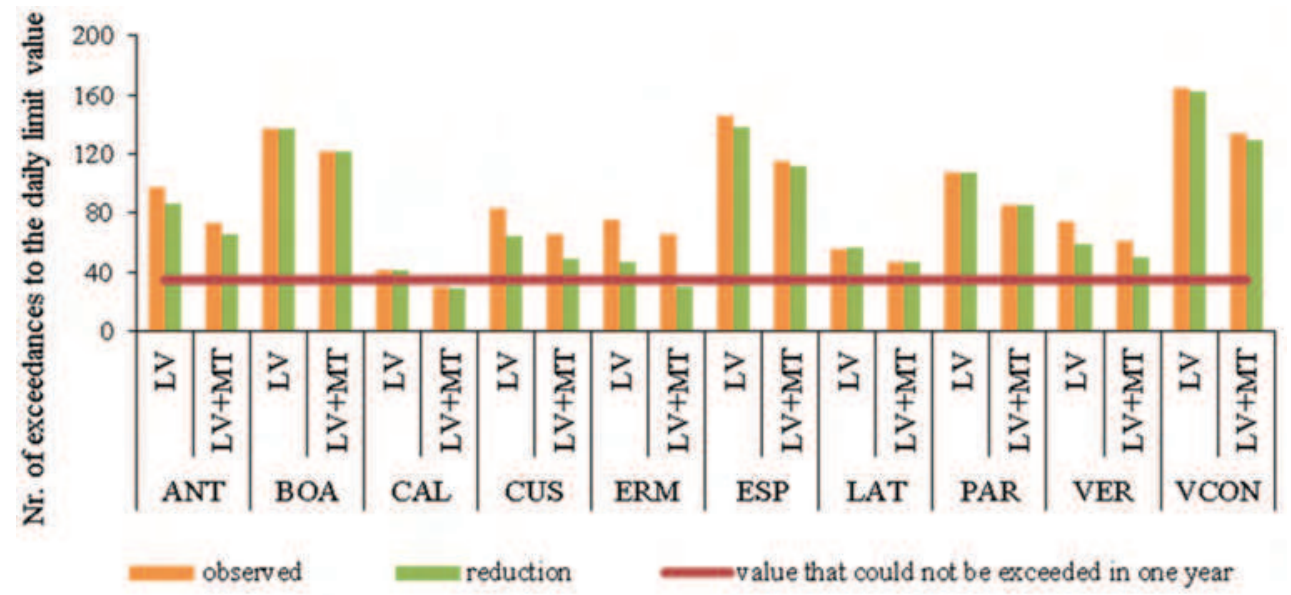

b)

Fig. 13. PM10 annual mean (a) and number of exceedances (b) for the observed values and for the observed values after the application of the reduction profile. 
Figure 13 shows that although the PM10 annual mean and the number of exceedances decrease in the selected air quality stations, the legislated limit values continue to be surpassed. Despite the efforts needed for the application of the selected measures, they lead to a slight decrease of the PM10 levels in the atmosphere. It should also be stated that air quality improvements can be achieved, although these are not sufficient to eliminate all the exceedances of the PM10 limit values that can be detected over the northern region of Portugal. However, it is important to reinforce the fact that not all the measures considered in the Air Quality Plan were considered in the reduction scenario simulation, since it was not possible to estimate the PM10 emissions' reduction associated with them (e.g., environmental education, construction sites). Therefore, considering all the measures contained in the Air Quality Plan, it is possible to achieve a higher decrease in the overall PM10 levels.

\section{Final comments}

In the northern region of Portugal high PM10 concentrations were measured at several agglomerations and, according to the European and national legislation, action plans must be designed and implemented to reduce these PM10 levels. For this purpose reduction measures have been defined at the local level for three main sectors: traffic, industry, and residential combustion. Also, measures related to construction activities and environmental education were developed. The impact of the measures on the air quality of Northern Portugal was the main objective of this study.

It was possible to conclude that the application of the selected reduction measures is important to improve the PM10 concentrations in the northern region. A decrease of the annual mean and of the number of exceedances was estimated at the air quality monitoring stations location. The modelling results for the reduction scenario show a PM10 annual averaged concentration decrease of almost $5 \mu \mathrm{g} \cdot \mathrm{m}^{-3}$ over the Porto urban area, which corresponds to a $19 \%$ maximum reduction. However, even after the application of the reduction measures, most of the air quality stations continue to surpass the legislated limit values. Thus, additional measures must be considered in order to fulfill the air quality requirements. The involvement of local authorities and stakeholders is very important, but some potential reduction measures, probably the most effective and efficient, should be taken at national level.

Finally, it should also be pointed out that under climate change conditions the northern region is one of the areas that will be most affected by changes in weather patterns, and predicted changes in the boundary layer height, relative humidity, temperature, solar radiation, wind speed and precipitation may be responsible for a significant impact in the PM10 levels in the atmosphere (Carvalho et al., 2010). The design and execution of additional measures is therefore even more important due to the current conditions, but also to the future climate change driving force.

\section{Acknowledgements}

The authors wish to thank the North Regional Coordination and Development Commission (CCDR-N) for their support. Also, the authors thank the Portuguese Foundation for Science and Technology for the PhD grant of E. Sá (SFRH/BD/60474/2009). 


\section{References}

Amato, F., Querol, X., Alastuey, A., Pandolfi, M., Moreno, T., Gracia, J., Rodriguez, P. (2009) - Evaluating urban PM10 pollution benefit induced by street cleaning activities, Atmospheric Environment 43, 4472-4480.

Bandeira, J.M., Coelho, M.C., Sá, M.E., Tavares, R., Borrego, C. (2011) - Impact of land use on urban mobility patterns, emissions and air quality in a Portuguese medium-sized city, The Science of Total Environment 409, 6, 1154-1163. doi:10.1016/j.scitotenv.2010.12.008.

Borrego, C., Miranda, A.I., Sousa, S., Carvalho, A., Sá, E., Martins, H., Valente, J., Varum, C., Jorge, S. (2008a) - Planos e Programas para a Melhoria da Qualidade do Ar na Região Norte - Uma visão para o período 2001-2006 (Plans and Programmes for the improvement of the air quality over the norther region - an overview over the perid 2001-2006), University of Aveiro, Portugal. AMB-QA-7/2008.

Borrego, C., Miranda, A.I., Monteiro, A., Tchepel, O., Martins, H., Tavares, R., Gonçalves, L. and Barbedo, P. (2008b) - Inventário das emissões de poluentes atmosféricos da Região Norte, Relatório R3 (Atmospheric polluttant emissions report for the northern region - report R3), Departamento de Ambiente e Ordenamento da Universidade de Aveiro.

Borrego, C., Valente, J., Carvalho, A., Sá, E., Lopes, M., Miranda, A.I. (2010a) - Contribution of residential wood combustion to PM10 levels in Portugal, Atmospheric Environment. 44, 642-651.

Borrego, C., Sá, E., Carvalho, A., Sousa, S., Miranda, A.I. (2010b) - Plans and Programmes to improve air quality over Portugal: a numerical modelling approach. Proceedings of the 13th International Conference on Harmonisation within Atmospheric Dispersion Modelling for Regulatory Purposes, 1-4 June, Paris, France.

Carvalho, A., Monteiro, A., Solman, S., Miranda, A.I. and Borrego, C. (2010) - Climatedriven changes in air quality over Europe by the end of the 21st century, with special reference to Portugal, Environment Science \& Policy I3, 445-458.

EEA (European Environment Agency), 2005: The European environment - State and outlook 2005. State of Environment report No 1/2005. Copenhagen.

Hurley, P.J., Physick, W.L., Luhar, A.K. (2005) - TAPM: a practical approach to prognostic meteorological and air pollution modelling, Environment Modelling and Software 20, 737-752.

Ketzel, M., Omstedt, G., Johanson, C., During, I., Gidhagen, L., Lohmeyer, A., Berkowicz, R., Wahlin, P. (2005) - Estimation and validation of PM2.5/PM10 exhaust and nonexhaust emission factors for street pollution modelling, Proceedings of the 5th International Conference on Urban Air Quality, eds. Ranjeet Sokhi, Millán M. Millán and Nicolas Moussiopoulos, Proceedings on CD-Rom. Valencia, Spain.

Monteiro, A., Miranda, A.I., Borrego, C., Vautard, R., Ferreira, J. and Perez, A.T. (2007) Long-term assessment of particulate matter using CHIMERE model, Atmospheric Environment 41, 7726-7738.

Ribeiro, C. (2005) - Aplicação de um Modelo Meteorológico e de Qualidade do Ar a Portugal (Application of a meteorological and air quality model over Portugal). Masters Science Thesis, University of Aveiro, Portugal. 
Rodriguéz, S.G. (2002) - Sources and processes affecting levels and composition of atmospheric particulate matter in the Western Mediterranean. PhD Thesis, Universidade Politécnica da Cataluna, Barcelona, Spain.

Tente, H., Gomes, P., Ferreira, F., Amorim, J.H., Cascão, P., Miranda, A.I., Nogueira, L., Sousa, S. (2011) - Evaluating the efficiency of Diesel Particle Filters in high-duty vehicles: field operational testing in Portugal. Atmospheric Environment (Accepted for publication) 


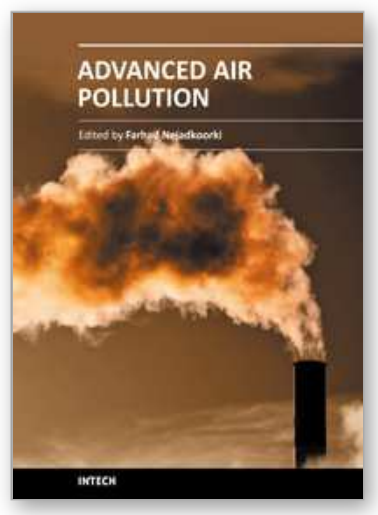

\author{
Advanced Air Pollution \\ Edited by Dr. Farhad Nejadkoorki
}

ISBN 978-953-307-511-2

Hard cover, 584 pages

Publisher InTech

Published online 17, August, 2011

Published in print edition August, 2011

Leading air quality professionals describe different aspects of air pollution. The book presents information on four broad areas of interest in the air pollution field; the air pollution monitoring; air quality modeling; the GIS techniques to manage air quality; the new approaches to manage air quality. This book fulfills the need on the latest concepts of air pollution science and provides comprehensive information on all relevant components relating to air pollution issues in urban areas and industries. The book is suitable for a variety of scientists who wish to follow application of the theory in practice in air pollution. Known for its broad case studies, the book emphasizes an insightful of the connection between sources and control of air pollution, rather than being a simple manual on the subject.

\title{
How to reference
}

In order to correctly reference this scholarly work, feel free to copy and paste the following:

C. Borrego, A.Carvalho, E. Sá, S. Sousa, D. Coelho, M. Lopes, A. Monteiro and A.I Miranda (2011). Air Quality Plans for the Northern Region of Portugal: Improving Particulate Matter and Coping with Legislation, Advanced Air Pollution, Dr. Farhad Nejadkoorki (Ed.), ISBN: 978-953-307-511-2, InTech, Available from: http://www.intechopen.com/books/advanced-air-pollution/air-quality-plans-for-the-northern-region-of-portugalimproving-particulate-matter-and-coping-with-I

\section{INTECH}

open science | open minds

\author{
InTech Europe \\ University Campus STeP Ri \\ Slavka Krautzeka 83/A \\ 51000 Rijeka, Croatia \\ Phone: +385 (51) 770447 \\ Fax: +385 (51) 686166 \\ www.intechopen.com
}

\author{
InTech China \\ Unit 405, Office Block, Hotel Equatorial Shanghai \\ No.65, Yan An Road (West), Shanghai, 200040, China \\ 中国上海市延安西路65号上海国际贵都大饭店办公楼 405 单元 \\ Phone: +86-21-62489820 \\ Fax: +86-21-62489821
}


(C) 2011 The Author(s). Licensee IntechOpen. This chapter is distributed under the terms of the Creative Commons Attribution-NonCommercialShareAlike-3.0 License, which permits use, distribution and reproduction for non-commercial purposes, provided the original is properly cited and derivative works building on this content are distributed under the same license. 